\title{
Comparative effectiveness of silvicultural interventions for increasing timber production and sustaining conservation values in natural tropical production forests. A systematic review protocol
}

Gillian Petrokofsky ${ }^{1 *}$, Plinio Sist ${ }^{2}$, Lilian Blanc ${ }^{2}$, Jean-Louis Doucet ${ }^{3}$, Bryan Finegan $^{4}$, Sylvie Gourlet-Fleury ${ }^{2}$, John R Healey ${ }^{5}$, Barbara Livoreil ${ }^{6}$, Robert Nasi ${ }^{7}$, Marielos Peña-Claros ${ }^{8}$, Francis E Putz ${ }^{9}$ and Wen Zhou $^{7}$

\begin{abstract}
Background: Currently, about 400 million hectares of tropical moist forests worldwide are designated production forests, about a quarter of which are managed by rural communities and indigenous peoples. There has been a gradual impoverishment of forest resources inside selectively logged forests in which the volume of timber extracted over the first cutting cycle was mostly from large, old trees that matured over a century or more and grew in the absence of strong anthropological pressures. In forests now being logged for a second and third time, that volume has not been reconstituted due in part to the lack of implementation of post-logging silvicultural treatments. This depletion of timber stocks renders the degraded forests prone to conversion to other land uses. Although it is essential to preserve undisturbed primary forests through the creation of protected areas, these areas alone will not be able to ensure the conservation of all species on a pan-tropical scale, for social, economic and political reasons. The conservation of tropical forests of tomorrow will mostly take place within human-modified (logged, domesticated) forests. In this context, silvicultural interventions are considered by many tropical foresters and forest ecologists as tools capable of effectively conserving tropical forest biodiversity and ecosystem services while stimulating forest production. This systematic review aims to assess past and current evidence of the impact of silviculture on tropical forests and to identify silvicultural practices appropriate for the current conditions in the forests and forestry sectors of the Congo Basin, Amazonia and Southeast Asia.

Methods: This systematic review will undertake an extensive search of literature to assess the relative effectiveness of different silvicultural interventions on timber production and the conservation value of forests, and to determine whether there is a relationship between sustainability of timber harvesting and the maintenance/conservation of other ecosystem services and biodiversity in production forests. Data will be extracted for meta-analysis of at least sub-sets of the review questions. Findings are expected to help inform policy and develop evidence-based practice guidelines on silvicultural practices in tropical forests.
\end{abstract}

Keywords: Silviculture, Tropical forests, Sustainable forest management, Conservation, Biodiversity

\footnotetext{
* Correspondence: gillian.petrokofsky@zoo.ox.ac.uk

'University of Oxford, Oxford, UK

Full list of author information is available at the end of the article
} 


\section{Background}

While tropical silviculture still remains little-known or poorly acknowledged among decision-makers, there is also some strong antagonism even within the forestry scientific community, namely between forest ecologists and conservation ecologists. The former defend silvicultural interventions as tools to stimulate forest production whereas the latter accept only the most gentle interventions and promote biodiversity conservation through the creation of protected areas even within production forests. One source of confusion and conflict is that depending on how it is carried out, logging can represent either forest exploitation or a major silvicultural intervention designed to maintain forest productivity. From the outset, tropical silviculture faced the problem of reconciling timber production with long-term conservation of forest ecosystems, though the main objective in the early days was indeed to improve timber production [1]. The main challenge lies in finding thresholds of extraction intensity coupled with silvicultural treatments that are compatible with: (1) the maintenance of biodiversity and the main ecosystem services targeted for a given forest management unit, (2) the profitability for the actors involved.

Although it is essential to preserve undisturbed natural forests through the creation of protected areas, these areas alone will not be able to ensure the conservation of all species on a pan-tropical scale, for social, economic and political reasons. According to SEDAC (http://sedac.ciesin. columbia.edu/data/collection/wildareas-v2, cited by Hobbs et al. [2]), 83\% of the land surface of the earth is impacted to some degree. Tropical forests are no exception, with (at most) only $1 / 2$ of them being considered primary [3]. The conservation of tropical forests of tomorrow will mostly take place within human-modified (logged, domesticated) forests, but only if they are well managed. "Well managed" means that the implemented forest management must guarantee the perpetuation of timber resources, along with biodiversity and most of the other ecosystem services provided by forests. With advances in the agricultural sciences and increased demand for plantation crops and agricultural commodities (e.g., palm oil and beef), the opportunity costs of forest retention have also increased of late. Counterbalancing that trend is the emergence of markets for the payment of ecosystem services provided by forests which opens up economic incentives to support the implementation of silvicultural treatments.

Currently, about 400 million hectares of tropical moist forests worldwide are designated production forests, about a quarter of which are managed by rural communities and indigenous peoples [3]. There is now clear evidence that, with current logging practices based on a single diameter cutting limit and a rotation cycle of around 30 years, timber volumes will not recover within this rotation cycle [4]. The only way to keep an economically viable commercial volume is to expand the pool of species harvested and/or to reduce the minimum cutting diameter [4-6]. Today this challenge is further exacerbated because most tropical forests have already been logged, and because there is a greater diversity of stakeholders in the forestry sector (farmers, communities, urban society), which was long dominated by large logging companies exploiting forest concessions for timber production. In these forests, the volume of timber extracted over the first cutting cycle was mostly from large trees that grew over several centuries in the absence of strong anthropogenic pressures. When these forests are re-logged, that volume has not been recovered and, in many cases, the young trees expected to make up the next harvest are lacking in numbers or have not yet attained larger sizes as no silvicultural treatments were applied to favour them [7]. Figure 1 illustrates this reduced yield over time in contrast with sustained yield after silvicultural treatments.

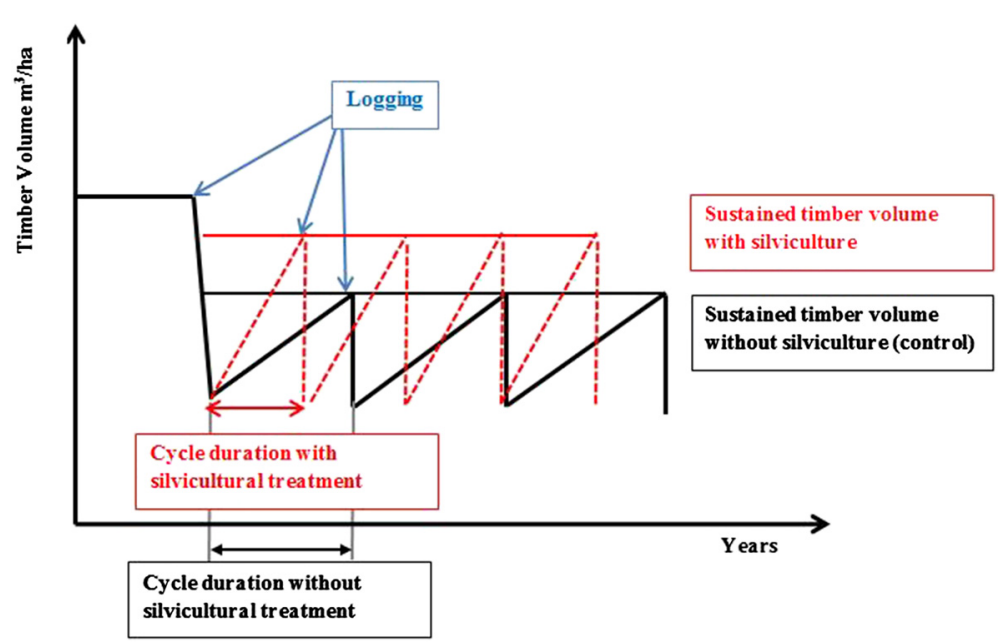

Figure 1 Expected impact of post-logging silviculture on both sustained timber volume and duration of rotation cycle. 
This depletion of commercial stocks of timber reduces the financial value of standing forest and puts the forests at risk of being further severely degraded and ultimately converted to other uses. This problem was highlighted in Africa and South-East Asia in the 1960s by foresters who originated from temperate countries and who undertook a large variety of silvicultural trials with the goal of enriching tropical forests with commercial species, by fostering their regeneration either naturally or artificially. Those trials involved contrasting technical operations, from full planting to liberation of naturally regenerated future crop trees by poison-girdling competitors. Those trials generated a considerable amount of data and knowledge that has mostly remained unavailable, published in technical reports and/or non-English language journals, and fully under-valued - or even forgotten - as logging has developed into a vast profitable 'mining' operation in most forests dedicated to production.

\section{Objective of the review}

A systematic review of the impact of past silvicultural practices, and not just logging, can inform us about the available opportunities for managing and restoring the economic and environmental values of natural tropical production forests. The main objective of this systematic review is therefore to assess past and current knowledge of the impact of silviculture on the conservation values of tropical forests (its natural capital, including biodiversity, and the full range of ecosystem services that it underpins) and to identify silvicultural approaches that are appropriate for the forests and forestry sectors of the Congo Basin, Amazon Basin, and tropical regions of Southeast Asia (Table 1 gives a full list of countries and regions included in the review). One important goal of this systematic review is to evaluate the compatibility of silviculture for enhanced timber production with the maintenance of other ecosystem services. In so doing, we want to address the following primary and secondary questions:

\section{Primary review question}

How do silvicultural interventions affect timber production and conservation values in natural tropical production forests?

\section{Secondary review questions}

1. How do different silvicultural treatments affect both production and conservation values?

2. Where silviculture for sustained timber harvests and maintenance/conservation of other ecosystem

Table 1 List of terms used to build the search string and define the inclusion perimeter of the papers retrieved

A. Geographical terms (countries and regions) (using spelling variants as appropriate)

Tropic* Or "Central America" Or "South America" Or Caribbean Or "Central Africa" Or "East Africa" Or "West Africa" Or "Southeast Asia" OR Mexico OR Belize OR "Costa Rica" OR "El Salvador" OR Guatemala OR Honduras OR Nicaragua OR Panama OR Bolivia OR Brazil OR Colombia OR Ecuador OR Guyana OR Galapagos OR Paraguay OR Peru OR Suriname OR Venezuela OR Anguilla OR "Antigua and Barbuda" OR Aruba OR Bahamas OR Barbados OR "Virgin Islands" OR Cayman Islands OR Cuba OR Dominica* OR Grenada OR Guadeloupe OR Haiti OR Jamaica OR Martinique OR Montserrat OR Antilles OR "Puerto Rico" OR "Saint Barthelemy" OR "Saint Kitts" OR Nevis OR "Saint Lucia" OR "Saint Martin" OR "Saint Vincent and the Grenadines" OR "Trinidad and Tobago" OR "Turks and Caicos" OR Angola OR Cameroon OR "Central African Republic" OR Chad OR Congo OR Zaire OR "Equatorial Guinea" OR Gabon OR Sudan OR Zambia OR Burundi OR Comoros OR Djibouti OR Eritrea OR Ethiopia OR Kenya OR Madagascar OR Malawi OR Mauritius OR Mayotte OR Mozambique OR Reunion OR Rwanda OR Seychelles OR Somalia OR Tanzania OR Uganda OR Benin OR "Burkina Faso" OR "Cote d'Ivoire" OR "Ivory Coast" OR Gambia OR Ghana OR Guinea* OR Liberia OR Mali OR Mauritania OR Niger* OR "Saint Helena" OR "Sao Tome and Principe" OR Senegal OR "Sierra Leone" OR Togo OR Brunei OR Burma OR Myanmar OR Cambodia OR "East Timor" OR Indonesia OR Laos OR "Lao PDR" OR Malaysia OR Philippines OR Thailand OR Vietnam OR India

\section{B. Population terms}

forests $O R$ rainforests $O R$ woods $O R$ woodlands $O R$ kerangas $O R$ cerrado OR wallaba OR varzea OR igapo OR terra firme OR mata atlantica
C. Intervention terms (using double quotes, and proximity operators, as appropriate)

PRE-HARVEST/PLANNING

permanent sample plot OR minimum cutting diameter OR diameter cutting limit OR harvest plan OR forest management plan OR cutting cycle OR diameter limit OR liana/liane cutting OR climber cutting OR riparian buffers OR sustainable forest management OR sustained timber yields OR future crop trees OR potential crop trees OR advanced regeneration OR felling cycle OR rotation cycle OR skid trails OR logging roads OR snig tracks OR logging gaps OR planting OR sowing OR nursery OR criteria OR forest certification OR inventory OR stock inventory $O R$ forest management unit HARVEST timber harvesting OR logging OR selective harvesting OR selective logging OR reduced-impact logging OR ril OR low-impact logging OR low-impact silviculture OR harvesting techniques OR logging damage OR yarding techniques OR seed tree retention OR shelterwood OR Malayan uniform system OR polycyclic OR monocyclic OR uneven-aged management OR even-aged management OR felling OR clear strip felling OR directional felling OR group felling OR tpti OR silin OR partial cutting OR patch cutting OR celos OR logging intensity OR selective management OR retention forestry OR annual coupe POST-HARVEST liberation thinning OR thinning OR girdling OR refinement OR poisoning OR poison-girdling OR enrichment planting OR line planting OR gap planting OR recovery rate OR reconstitution rate OR assisted natural regeneration OR topsoil removal OR regrowth method OR liana cutting

\section{CAB Abstracts search variant}

Set A AND (silvicultur*.ab. OR silvicultur*.ti. OR silvicultur*.de. OR KK110.cc. ${ }^{a}$ OR logging.ab. OR logging.ti. OR logging.de. OR deforest*.ab. OR deforest*.ti. OR deforest*.de. OR forest management.de. OR forest inventories.de.) (See EndNote for explanation of field limits specified here) 
services and biodiversity has been practiced, how do differences in these treatments affect socio-economic outcomes?

\section{Methods}

This systematic review will undertake an extensive search of literature to assess the impacts of different silvicultural interventions on timber production and the conservation value of natural tropical forests, and to further determine whether these outcomes can both be achieved by the same interventions and how different silvicultural interventions for combined sustained timber harvests and maintenance/conservation of other ecosystem services and biodiversity affect socio-economic outcomes. Data will be extracted for meta-analysis of at least a sub-set of the review questions. Findings are expected to help inform policy and develop evidence-based practice guidelines on the value (or otherwise) of silvicultural practices in tropical natural forests.

\section{Search strategy}

Given that the scope of this systematic review is broad and that it can be difficult to identify relevant studies from titles and abstracts, the authors are aware of the necessity of balancing comprehensiveness with specificity in the searches. "Forest management", for example, is in general a broader concept than the focus of this review, but "silviculture" alone is too narrow. A subgroup of authors tested various search strategies, using combinations of key words and phrases suggested in an initial two-day scoping meeting. These strategies were tested against a reference list of papers (see Additional file 1: Annex1) to refine the search and maintain a balance between, at the one end, extracting an unwieldy set of forestry references from the 1920s onwards which 'might' contain a table of useful data, and, at the other end, a narrow set of papers with known useful data, which is not representative of the overall body of evidence. Keywords and phrases for searches in the main bibliographic databases (indicated by an asterisk in Table 2) were derived from the following PICOs listed below. The terms and search logic are shown in Table 1. We recognise the importance of studies published in languages other than English. The search strategy will therefore be applied (and documented carefully for peer review) to the following languages: English, French, Spanish, Portuguese, German, and Dutch, subject to time and resources. Where time and resources permit, and recognizing the potentially high cost of translating relevant studies, we will also search in: Bahasa Indonesia, Japanese, and Thai.

\section{PICOs}

\section{Population}

Closed canopy natural forest used for timber production in the tropics (= natural tropical production forests).
Table 2 Databases and websites

\begin{tabular}{ll}
\hline Bibliographic databases & Grey literature \\
\hline *Web of Science & Institutions \\
${ }^{*}$ CAB Abstracts (with particular & Forest Research \\
focus on the Forestry \& Forest & Institute of \\
Products Abstracts subset) & Malaysia \\
*Scopus & FAO \\
Agricola & USDA Forest Service \\
Agris & US Fish and Wildlife Service \\
BioONE & USAID \\
SciELO & GIZ \\
JSTOR & ICRAF \\
Index to Theses Online & CIFOR \\
Directory of Open Access Journal & CATIE \\
ProQuest & Agritrop (CIRAD) \\
& IITF \\
Web searches & Embrapa \\
Google & Royal Museum for Central Africa \\
Google Scholar & National Botanic Garden of \\
& Belgium \\
\hline
\end{tabular}

*Asterisks relate to sources which will be searched using Table 1 strategy.

(A full list of countries and regions in the tropics is included in Table 1).

\section{Interventions}

Any silvicultural activity, including pre-harvest, harvesting (logging), post-harvest treatments, construction of secondary roads and skid trails (A full list of silvicultural activities is included in Table 1).

\section{Comparator}

Temporal or spatial comparisons of silvicultural practices.

\section{Outcomes}

Increase of timber yield or timber volume recovery, or changes in ecological conditions of the forest or socioeconomic outcomes (latter only if studies also reporting timber yield and ecological condition outcomes).

\section{Other}

In addition to systematic searching (as above), a call for grey literature will be issued to stakeholders, including through the IUFRO subgroup on tropical silviculture, the International Society of Tropical Forests, LinkedIn and Research Gate and the personal contacts of authors. References in relevant books will also be searched as time and resources permit. 


\section{Search terms \& Boolean logic}

Searches in CAB Abstracts, Web of Science and Scopus will be based on the logic A AND B AND C, where A-C are the sets of terms listed in Table 1. Within each set, alternative terms will be searched, using OR. CAB Abstracts, having a sub-database dedicated to forestry, will be searched using a modified strategy that makes use of CABICODES and descriptors from the CAB Thesaurus (Table 1 - section D). The search was devised in consultation with the Editor of Forestry Abstracts, and the former editor of Forest Products Abstracts (one of the review authors). In our scoping studies a simpler search performed better than the strategy used for Scopus and Web of Science. A much simpler search strategy, based on that devised for $\mathrm{CAB}$ Abstracts, but excluding the CABICODES, will be used to search resources that cannot accommodate complex search strings. These are NOT marked with an asterisk in Table 2.

\section{Inclusion criteria}

Studies will be included if they are from populations in the target countries or regions (Table 1), and include information on the silvicultural (and other) interventions and outcomes set out in the PICO list above. It is likely that a larger set of relevant Outcomes will be included once reviewers screen the full text of papers. Consequently, a complete list of silvicultural interventions and outcomes will be documented iteratively as these emerge. A subgroup of authors will select papers retrieved from the searches, following removal of duplicates. A preliminary inclusion/ exclusion assessment of a randomly selected set of 100 articles will be conducted to test consistency between researchers' screening judgment. Cohen's Kappa metrics will be used to indicate a measure of consistency. A consistency co-efficient of 0.6 or greater is usually accepted as sufficient in the literature [8]. The first stage of inclusion/exclusion will entail screening for relevance of articles by title only. This stage will be followed by screening using titles and abstracts together; finally the assessment will be based on reading the full text. At each stage, studies will remain in the set to be included if they MAY contain relevant information about silvicultural interventions or outcomes. This will help reduce the possibility that we are overly-restrictive about relevant outcomes at the outset. Results of screening will be documented (including reasons for exclusion) and will be available as supplementary material to the systematic review paper.

\section{Exclusion criteria}

Papers will be excluded if they are exclusively about

- mangroves or woodlands (e.g. miombo) or pure conifer forests
- agroforestry systems

- tree plantations following clear-cutting

\section{Effect modifiers}

The following will be recorded, where available, as potential effect modifiers and sources of heterogeneity:

\author{
Geographical location \\ Altitude \\ Climate \\ Soil type \\ Time after logging or any other silvicultural \\ intervention \\ Dominant tree species \\ Type, duration and intensity of silvicultural activity and \\ logging intensity \\ Time elapsed from silvicultural intervention to \\ sampling \\ Land use and history of land use in the neighbouring \\ landscape \\ Proximity to urban centres (which have different sizes, \\ socio-economic status, etc.)
}

\section{Critical appraisal of studies}

Studies included in the review after full text screening will be critically appraised for study design, the robustness of their study design and the extent to which authors have attempted to limit biases.

Variables outlined in Table 3 will be used to construct a list from which the quality of individual studies can be assessed. Studies will be categorised as having high or low susceptibility to bias on the basis of presence/absence of replication, measures of variance and potential effect modifiers. Studies with high susceptibility to bias will not be excluded from the narrative review, but they will be subjected to sensitivity analysis following Brooks et al. [9]. We are aware of the proposal by Bilotta et al. [10] that environmental systematic reviews should adapt the Environmental- Risk of Bias Tool and we will check the feasibility of this approach for our set of studies. We know that our review will include a number of older studies and we are aware of advances in study design in recent decades, and also of the general problem of pseudo-replication in published studies [11], and presumably also in unpublished studies that may be included in our review, and we will amend our proposed critical appraisal method if (a) it is too difficult to apply by reviewers (requiring subjective judgment that is difficult to standardise across reviewers, despite repeated kappa analysis), and (b) the criteria are too 'strict' (resulting in a very small set of studies that are considered to be of sufficiently high quality to be included for quantitative analysis in the review). 
Table 3 Criteria for critical appraisal and data extraction from studies selected after full text screening

\begin{tabular}{|c|c|c|}
\hline Main sections & Criteria for critical appraisal & Data extracted \\
\hline \multirow{3}{*}{$\begin{array}{l}\text { Description of the } \\
\text { study site }\end{array}$} & & Latitude and longitude of sites \\
\hline & & Data on climate, topography, geology and soils \\
\hline & & Population size, main cities, main economic activities \\
\hline \multirow[t]{2}{*}{ Population } & & $\begin{array}{l}\text { Type of forest indicated from which a standard list can be compiled } \\
\text { for ease of comparison }\end{array}$ \\
\hline & & $\begin{array}{l}\text { Basal area, timber volume before logging, biomass, number of trees, } \\
\text { and other inventory metrics (to be developed iteratively) }\end{array}$ \\
\hline \multirow[t]{5}{*}{ Methods } & Clear and repeatable methodology & Number of plots, treatments, blocks, replications (see also below) \\
\hline & Adequate description of silvicultural treatments & $\begin{array}{l}\text { Logging intensity ( } \mathrm{m}^{3} / \text { ha, basal area removed, number of trees removed, } \\
\text { biomass removed) }\end{array}$ \\
\hline & Replication - at least 3 plots or treatments & Number of plots/treatment \\
\hline & Outcome measured after intervention & Number of years after silvicultural intervention \\
\hline & Spatial autocorrelation between transects & \\
\hline \multirow[t]{10}{*}{ Results } & Validity or reliability of data & Data for mean and SD \\
\hline & & Size of the sample \\
\hline & Randomized sample & $\mathrm{Y} / \mathrm{N}$ \\
\hline & $\begin{array}{l}\text { Variables measured allow the effect of } \\
\text { the intervention to be assessed }\end{array}$ & \\
\hline & & $\%$ recovery of timber volume \\
\hline & & $\%$ recovery of biomass \\
\hline & & Biodiversity (floristic, faunistic, indicators) \\
\hline & & Other quantification or indicators of ecosystem services \\
\hline & & $\begin{array}{l}\text { Measures of socio-economic outcome (including poverty, human health } \\
\text { \& well-being, livelihoods, social capital, social welfare, empowerment, } \\
\text { equity, based on Pullin et al. (2013) [14]) }\end{array}$ \\
\hline & & Type of models (matrix, individual based) \\
\hline
\end{tabular}

\section{Data synthesis and presentation}

A narrative synthesis of data from all studies included in the review will describe the quality of the results along with the study findings. Tables will be produced to summarise these results. Where studies report similar outcomes, meta-analysis may be possible. In these cases effect sizes will be standardised and weighted appropriately. Details of the quantitative analysis will emerge once full-text screening has yielded a set of studies that can be assessed for content and quality.

Subgroup analysis of categories of studies will also be performed where sufficient studies report common sources of heterogeneity. In addition to publication bias (see below), sensitivity analysis will be carried out where possible following Brooks et al. [9]. Silvicultural effects will be presented visually in plots of mean effect sizes and variance. If meta-analysis of effect sizes is possible, it will take the form of random-effects models, and meta-regression will be performed where effect modifiers cause significant heterogeneity between studies.

\section{Publication bias}

There is evidence that in many research areas papers are more likely to be published if they demonstrate clear, positive results (or strong negative effects), and that papers that show little or no effect are less likely to be published. To assess the possibility of such publication bias, we will compare studies in the unpublished 'grey' literature with studies in academic journals [12] to assess whether there is evidence of publication bias. If data allow, we will assess bias using funnel plots, which show effect sizes and standard error or sample sizes [13].

\section{Endnote}

${ }^{\mathrm{a}}$ For the $\mathrm{CAB}$ Abstracts database, searching is limited to Title, Abstract and keyword fields using the field limiters shown in Table 1. Web of Science and Scopus have a default search mode that interrogates only those fields, which will be used. This eliminates papers that contain any of our keywords in, for example, journal titles, institution addresses, etc.

KK110 is one of a suite of CABICODES, which are applied as additional indexing categories by abstractors 
compiling $\mathrm{CAB}$ Abstracts. It relates to Forest management \& Silviculture. For a full list see http://www.cabi.org/ Uploads/CABI/publishing/training-materials/additionalresources/cabi-codeguide.pdf.

\section{Additional file}

Additional file 1: Annex1. Reference list to test search

comprehensiveness.

\section{Competing interests}

The authors declare that they have no competing interest.

\section{Authors' contributions}

All authors discussed the review title in a 2-day workshop, agreed the scope and extent of the review, and contributed to the draft. All have read and agreed the Protocol. The full systematic review will be under the leadership of Plinio Sist.

\section{Acknowledgements}

We acknowledge the financial support of the Center for International Forestry Research (CIFOR) from their Evidence-Based Forestry programme that is funded primarily by the UK Department for International Development (DFID) through their KNOW-FOR grant to CIFOR.

\section{Author details}

${ }^{1}$ University of Oxford, Oxford, UK. ${ }^{2}$ Cirad, Montpellier, France. ${ }^{3}$ Université de Liège, Gembloux Agro-Bio Tech, Liège, Belgium. ${ }^{4}$ Catie, Turrialba, Costa Rica. ${ }^{5}$ Bangor University, Bangor, UK. ${ }^{6}$ Fondation pour la Recherche sur la Biodiversité, Paris, France. ${ }^{7} \mathrm{CIFOR}$, Bogor, Indonesia. ${ }^{8}$ Wageningen University, Wageningen, Netherlands. 'University of Florida, Gainesville, FL, USA and CIFOR.

Received: 21 November 2014 Accepted: 3 March 2015

\section{Published online: 15 April 2015}

\section{References}

1. Dawkins HC, Philip MS. Tropical moist forest silviculture and management: a history of success and failure. Wallingford, UK: CAB International; 1998. p. 359. ISBN 0-85199-255-2.

2. Hobbs RJ, Higgs E, Harris JA. Novel ecosystems: implications for conservation and restoration. Trends Ecol Evol. 2009;24:599-605.

3. Blaser J, Sarre A, Poore D, Johnson SL. Status of tropical management. ITTO Technical Series, Yokohama, Japan. No. 382011 p. 460.

4. Putz FE, Zuidema PA, Synnott T, Pena-Claros M, Pinard MA, Sheil D, et al Sustaining conservation values in selectively logged tropical forests: the attained and the attainable. Conservation Letters. 2012;5:296-303.

5. Sist P, Gourlet-Fleury S, Nasi R. IUFRO international conference report: What future is there for tropical forest silviculture? Bois et Forêts des Tropiques. 2011;310:3-6.

6. Gourlet-Fleury S, Mortier F, Fayolle A, Baya F, Ouedraogo D, Benedet F, et al. Tropical forest recovery from logging: a 24 year silvicultural experiment from Central Africa. Philos Trans R Soc Lond B Biol Sci. 2013;368:20120302.

7. Catinot R. Sylviculture tropicale en forêt dense africaine [Tropical silviculture in African moist forest]. Bois et Forêts des Tropiques. 1965:100:5-18.

8. Cohen J. A coefficient of agreement for nominal scales. Educ Psychol Meas. 1960;20:37-46.

9. Brooks J, Waylen KA, Mulder MB. Assessing community-based conservation projects: A systematic review and multilevel analysis of attitudinal, behavioral, ecological, and economic outcomes. Environ Evid. 2013;2:2.

10. Bilotta GS, Milner AM, Boyd IL. Quality assessment tools for evidence from environmental science. Environ Evid. 2014:3:14.

11. Ramage BS, Sheil D, Salim HM, Fletcher C, Mustafa NZ, Luruthusamay JC, et al. Pseudoreplication in tropical forests and the resulting effects on biodiversity conservation. Conserv Biol. 2013;27:364-72.
12. Pullin A, Bangpan M, Dalrymple S, Dickson K, Haddaway NR, Healey JR, et al. Human well-being impacts of terrestrial protected areas. Environ Evid. 2013;2:19.

13. Leimu R, Koricheva J. What determines the citation frequency of ecological papers? Trends Ecol Evol. 2005;20:28.

14. Sterne JA, Jüni $P$, Schulz KF, Altman DG, Bartlett C, Egger M. Statistical methods for assessing the influence of study characteristics on treatment effects in 'meta-epidemiological' research. Stat Med. 2002;21:1513-24.

\section{Submit your next manuscript to BioMed Central and take full advantage of:}

- Convenient online submission

- Thorough peer review

- No space constraints or color figure charges

- Immediate publication on acceptance

- Inclusion in PubMed, CAS, Scopus and Google Scholar

- Research which is freely available for redistribution 